\title{
O ENSINO JURÍDICO DE DISCIPLINAS VOLTADAS AO ACESSO À JUSTIÇA: ESTUDO DE CASO
}

\section{THE LEGAL EDUCATION OF DISCIPLINES FOCUSED ON ACCESS TO JUSTICE: CASE STUDY}

\author{
Daniel Mota Gutiérrez ${ }^{1}$ \\ Victor Alves Magalhães ${ }^{2}$
}

\section{RESUMO}

O objetivo deste ensaio foi compreender a importância do acesso à justiça na legislação promovida pelas Diretrizes Curriculares Nacionais dos Cursos de Direito e como esse princípio vem sendo tratado atualmente, analisando-se a organização das matrizes curriculares dos cursos no Ceará. Os métodos utilizados foram estudo de caso e bibliografia qualitativa sobre a temática. Os resultados alcançados refletem a hipótese de que outros fatores, além da formação dos discentes, são influenciadores dos dados governamentais, chegando-se a percepção que para que o Acesso à Justiça alcance algum dia o status almejado quando foi insculpido, são necessários todos os agentes do Direito.

Palavras chave: Acesso à Justiça; Ensino Jurídico; Estudo de Caso; Matrizes curriculares; Diretrizes Curriculares Nacionais

\begin{abstract}
The objective of this essay was to understand the importance of access to justice in the legislation promoted by the National Curricular Guidelines of Law Courses and how this principle is being treated today, analyzing the organization of curricular matrices of the courses in Ceará. The methods used were a case study and a qualitative bibliography on the subject. The results obtained reflect the hypothesis that other factors, besides the formation of the students, are important, bringing the perception to reach the desired status to the Access to Justice, all the agents of Law are necessary.
\end{abstract}

Keywords: Access to justice; Legal Education; Case study; Curricular arrays; National

\footnotetext{
${ }^{1}$ Professor da Graduação e Pós-Graduação do Centro Universitário Christus de Fortaleza (Ceará, Brasil). Doutor em Direito pela Pontifícia Universidade Católica de São Paulo (Brasil). Mestre em Direito pela Pontifícia Universidade Católica de São Paulo (Brasil). Advogado. E-mail: dgutierrez@uol.com.br

${ }^{2}$ Mestrando em Direito pela Universidade Federal do Ceará (Fortaleza - Brasil). Pós-Graduando em Gestão Educacional pela Faculdade Damásio (São Paulo - Brasil). Graduado em Direito pela Universidade Federal do Ceará (Fortaleza - Brasil). Pesquisador e Bolsista CAPES. E-mail: victoralvesmagal@gmail.com
} 
Curriculum Guidelines.

\section{INTRODUÇÃO}

A problemática deste ensaio surge com a liderança do estado do Ceará, por meio de dados oficiais promovidos pelo Conselho Nacional de Justiça (CNJ) em seus índices de conciliação, quando comparados com os demais membros da federação brasileira, associado com as dificuldades com que o Judiciário vem atravessando para melhorar tais números de conciliação em nível nacional.

Vislumbrou-se, assim, a hipótese de existir alguma espécie de diferencial na formação dos profissionais do Direito no referido estado, ao se tratar do Acesso à Justiça em seu sentido mais amplo, promovendo-se assim um estudo de caso sobre os quatro cursos de graduação em Direito que possuem pós-graduação stricto sensu no estado do Ceará - explicando-se tal corte metodológico por ser possível supor que estes cursos são os de maior excelência no estado, já que são os únicos, atualmente, que conseguiram criar programas de mestrado (sendo dois desses quatro com programas de doutorado também) e, por esse motivo, acabam influenciando como "modelos" aos demais da região - e suas atuais matrizes curriculares de ensino, para averiguar quanto da carga horária discente é dedicada ao estudo do acesso à justiça e quais disciplinas que viabilizariam esse aprendizado de alguma maneira.

Antes disso, contudo, foi levantada bibliografia qualitativa sobre a temática, apontado como a legislação sobre o ensino jurídico vem tratando e pretende lidar com tal área no âmbito das Diretrizes Nacionais Curriculares do Curso de Direito.

O objetivo, portanto, deste ensaio, foi compreender a importância do acesso à justiça na legislação concernente ao ensino jurídico e como esse princípio vem sendo tratado em um caso concreto, cujo local os números do $\mathrm{CNJ}$ indicam possuir a melhor incidência de acordos do país, buscando-se descobrir se seria viável cogitar alguma relação entre esses dados.

Justifica-se tal estudo pela importância estabelecida ao Acesso à Justiça e os direitos que gravitam em torno dessa (direitos culturais, proteção de minorias, meios consensuais de solução de conflitos, etc.) por meio da nova Resolução, publicada em dezembro de 2018, que versa sobre as novas diretrizes curriculares para o ensino do Direito, associado ao fato do Brasil enfrentar uma constante crise de litigiosidade, expressa em números anualmente pelos levantamentos feitos no Justiça em Números do CNJ. Afinal, acredita-se que tal enfoque na 
formação dos bacharéis possa auxiliar na qualidade do serviço Judiciário que o brasileiro recebe, porém aqui se reforça que não apenas disso poderá se acreditar que irá surgir um remédio para curar a mazela da falta de efetividade e eficiência da prestação jurisdicional no Brasil.

\section{IMPORTÂNCIA DO ENSINO RELATIVO AO ACESSO À JUSTIÇA}

O Judiciário brasileiro - com o advento do neoconstitucionalismo após a segunda guerra mundial e, sobretudo, com a influência dos diversos textos constitucionais que começaram a florescer após esse período, sendo a Constituição da República Federativa do Brasil (CRFB) de 1988 um dos marcos deste movimento - parece que sempre atravessou uma espécie de "crise estrutural", instituída com a redemocratização do país, quando a Constituinte lhe atribuiu papel central na estrutura do Estado, com um protagonismo consagrado pelo princípio da inafastabilidade da tutela jurisdicional, versado pelo inciso XXXV do artigo $5^{\circ}$ da CRFB de 1988 (WOLKMER, 2013).

Apesar do visível intuito do legislador originário, em sua ânsia de proteger as garantias e direitos tolhidos pelas duas décadas de uma ditadura ainda muito recente na história nacional, começou-se a perceber que o foco excessivo no Poder Judicante passou a refletir-se no enfraquecimento de outros meios capazes de proteger e efetivar o devido retorno daquilo que foi constitucionalmente estabelecido pela Constituição (CAPPELLETTI e GARTH; 1988).

Além disso, a institucionalização que o Judiciário - por meio de seus principais integrantes (magistrados) - seria competente para resolver todos os problemas de uma população que ultrapassa duzentos milhões de habitantes, somado com as benesses da Justiça Gratuita, acabou causando uma grande dependência da população brasileira com seus juízes, que finalizou o ano de 2017 com mais de oitenta milhões de processos em tramitação (BRASIL, 2018b), número que vem aumentando ao longo dos anos, pois o Judiciário não possui a capacidade de fornecer vazão na mesma proporção que é demandado.

Assim, em face do alto número de demandas apresentadas perante o Judiciário, passando a comprometer, dessa forma, a própria efetividade dos direitos e garantias que deveriam ser proporcionados por esse, fez-se necessária uma revisão do papel atribuído pelos constituintes originários aos juízes, iniciada em 2004 com a Emenda Constitucional $n^{\circ} 45$, que concedeu ao "acesso à justiça" a condição de garantia fundamental do ordenamento jurídico brasileiro. 
Contudo, os números do CNJ demonstram que "em média, a cada grupo de 100.000 habitantes, 12.519 ingressaram com uma ação judicial no ano de 2017 [...]." (BRASIL, 2018, p. 78), excluindo-se desse cálculo as execuções judiciais iniciadas em 2017. Além disso, apesar do crescimento exponencial dos Centros Judiciários de Solução de Conflitos e Cidadania (CEJUSCs) no Brasil - pois em 2015 existiam 654 centros, em 2016 o número foi para 808 e em 2017 chegou a 982 -, percebe-se na figura abaixo que o índice de conciliações se manteve quase estagnado ao longo dos anos:

Figura 1: Série Histórica do Índice de Conciliação

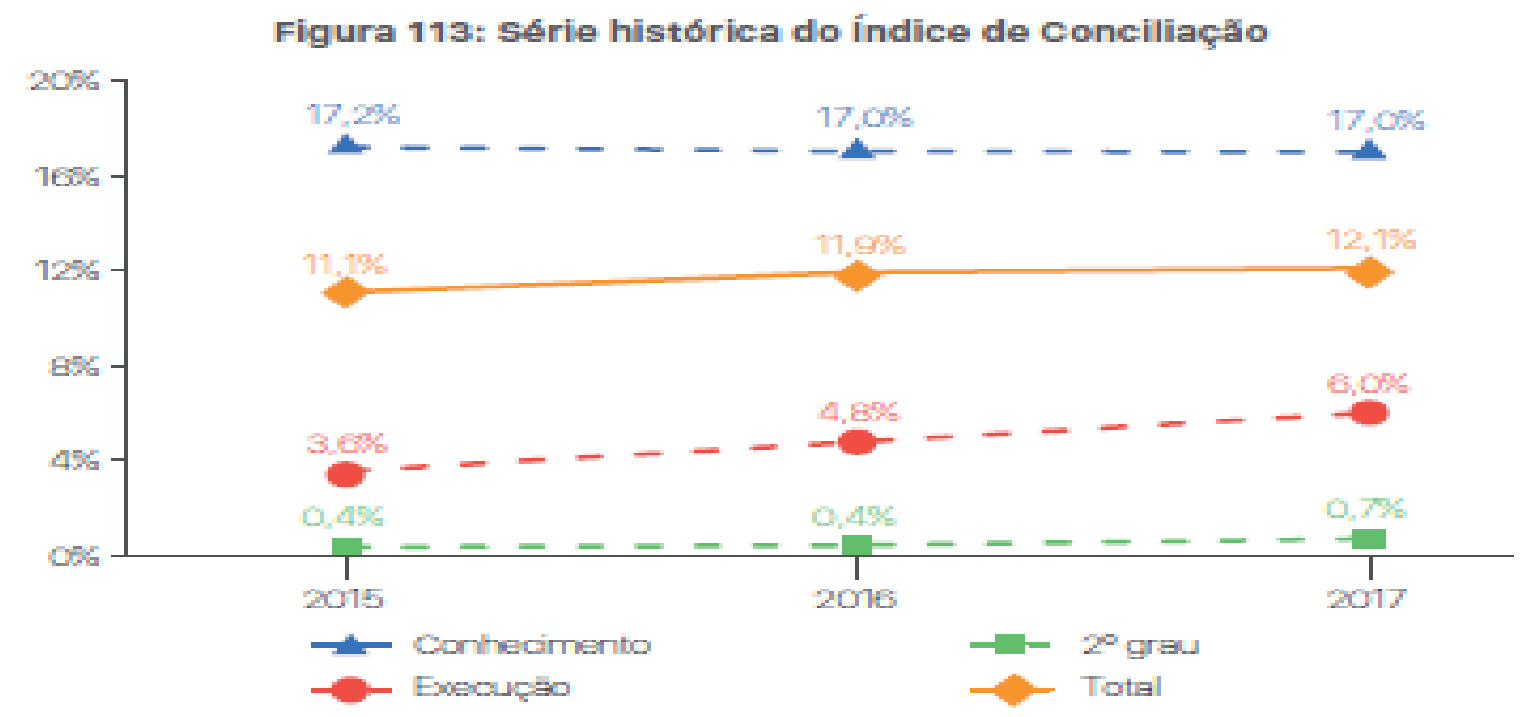

Fonte: BRASIL, 2018, p. 137

Dessa forma, podemos perceber que apesar dos esforços do CNJ e do Judiciário para aumentar o acesso à justiça aos jurisdicionados, apenas se nota com tais números que as portas de entrada das cortes são gigantescas, mas que existe um gargalo na saída, que acaba por não efetivar tal princípio completamente.

Possuindo agora tais dados concretos em mente, o autor Marcelo Neves, afirma que o “[...] Estado deixou de ser um locus privilegiado de solução de problemas constitucionais" (2009, p. 297) algo que, conseguintemente, evidencia que o mesmo também não precisa ser a única forma para a resolução de conflitos na sociedade brasileira, afinal, não vem sendo mais viável alocar no Judiciário todos os casos que surgem exponencialmente em face da necessidade, crescimento e complexidade de uma população que busca primeiramente nos juízes uma solução para os seus problemas. 
Portanto, acredita-se que o enfoque no acesso à justiça, seja pela via dos meios consensuais de solução de conflitos e pelo conhecimento dos direitos voltados às garantias individuais e culturas diversas que existem em nosso país (direitos humanos e fundamentais, direitos de minorias, direitos indígenas, direitos das crianças, adolescentes e idosos e etc.), deve surgir ainda na formação do profissional do Direito em sua graduação. Afinal, caso esses que trabalharão com o Direito não consigam uma formação apropriada nessas temáticas, como poderíamos exigir da população leiga o conhecimento de que o Judiciário não é a única via possível para resolução dos seus conflitos?

Coadunamos, neste aspecto, com o posicionamento de Andréa Marocco, quando essa afirma que é "evidente que, para se chegar a um estágio de compreensão do profissional do Direito, como ser humano pensante e transformador torna-se necessária a ultrapassagem, a superação, a singular compreensão, ao menos, inicialmente, de inúmeros desafios." (MAROCCO, 2012, p.77). Portanto, pautados nesta visão, que este ensaio promove o debate de um desses desafios que precisarão ser enfrentados na interpretação do profissional do Direito, em face do mundo moderno e de uma realidade regional atual.

\subsection{Exigências legais relativas às disciplinas voltadas para o Acesso à Justiça}

As novas Diretrizes Curriculares Nacionais (DCN) de Direito deverão fornecer ao graduando capacidade para que suas competências cognitivas, interpessoais e instrumentais sejam reveladas. Após leitura da análise comparativa feita por Stephane Lima, em sua dissertação, entre as Diretrizes de 2004 e a proposta que estava sendo concebida na época (publicada como Resolução em dezembro de 2018), percebeu-se que existe "[...] uma vontade de se efetivar e aprofundar o ensino do Direito em um viés de formação de competências mais práticas que permitam aos juristas uma atuação mais efetiva no mundo" (LIMA, 2018, p.60). Coaduna-se com o pensamento da autora, quando essa demonstra que diversos pontos são apenas reproduções ou atualizações de quesitos já existentes.

Como destaques referentes ao ensino, contudo, vale apontar nesta nova proposta de norma educacional (e para os propósitos deste trabalho) a aceitação de culturas diversas, bem como o enfoque também voltado para práticas negociais e processuais, recebendo os meios consensuais no seio da universidade (LIMA, 2018, p.59). Sendo tais direcionamentos intrinsecamente ligados ao acesso à justiça.

Entre a Resolução n..$^{\circ}$ 9/2004 do Conselho Nacional de Educação (CNE) e a Resolução 
n $5 / 2018$ do mesmo órgão, que versam sobre as Diretrizes Curriculares Nacionais do Curso de Graduação em Direito, percebemos atualizações quanto aos referidos assuntos e aspectos que ainda estão por melhorar desde 2004 nas matrizes curriculares atuais dos cursos analisados.

O primeiro descompasso entre a normativa de 2004 (já que os cursos possuem até o final do ano de 2020 para se adaptarem às novas Diretrizes publicadas em 2018), com o acesso à justiça que podemos notar, é o relativo com as próprias normas legais do CNE e com a Emenda Constitucional $n^{\circ} 45$, que concedeu ao "acesso à justiça" a condição de garantia fundamental do ordenamento jurídico brasileiro, conforme já exposto anteriormente.

Afinal, há quase quatorze anos essa garantia fundamental existe na Constituição Federal de 1988, sendo que, pelo ponto de vista doutrinário, desde o final da década de oitenta, que o acesso à justiça vem sendo encarado como o requisito fundamental de um sistema jurídico moderno e igualitário que pretenda garantir e não apenas proclamar os direitos de todos (CAPPELLETTI e GARTH; 1988).

Dessa forma, percebemos uma deficiência do ensino jurídico não apenas em relação ao ordenamento normativo educacional, mas quanto ao próprio sistema jurídico brasileiro, em debates que vêm ocorrendo na doutrina há trinta anos, mas que apenas superficialmente atingiram as matrizes curriculares estudadas, conforme irá ainda se expor.

Ainda nesse sentido, caso analisado pela ótica da Resolução $n^{\circ}$ 5/2018, que atualizou a normativa de 2004, nota-se que ainda maior será o esforço dos cursos para adequar sua realidade ao que poderá ser exigido.

Nesse sentido, dentro da organização curricular da nova Resolução, que prevê a necessidade do Projeto Pedagógico do Curso (PPC) ter formas de transversalidade dos conteúdos exigidos, é possível ilustrar tais exigências com questões que envolvam educação ambiental, educação em direitos humanos, educação para a terceira idade, educação em políticas de gênero, educação das relações étnico-raciais e histórias e culturas afro-brasileira, africana e indígena, entre outras (RODRIGUES, 2018, p. 29-34).

Dentro do perfil do graduando que será exigido, expressamente foi colocado o "domínio das formas consensuais de composição de conflitos" no artigo terceiro da Resolução de 2018.

Ainda na nova Resolução, nas habilidades e competências que precisarão ser desenvolvidas no discente que são listadas no artigo quarto, os incisos VI, VIII, X e XIV deixam claro que essas envolvem o fomento à cultura do diálogo e dos meios consensuais, devendo os 
alunos aprenderem a aturar em diversas instâncias (inclusive extrajudiciais), aceitar a diversidade e o pluralismo cultural e desenvolver perspectivas transversais sobre direitos humanos, respectivamente.

Relacionado à formação técnico jurídica do discente, dentro do inciso II do artigo quinto da Resolução $n^{\circ} 5 / 2018$, é notório o reforço da necessidade do profissional ser versado na Mediação, Conciliação e Arbitragem. Além disso, existe um fortalecimento nos três parágrafos do referido artigo, no que tange a necessidade da transdisciplinaridade e a preparação do profissional do Direito para os Direitos Humanos, Direito da Criança e do Adolescente, Direito Agrário, entre outros.

Em face da prática jurídica, temos no sexto parágrafo do artigo sexto a necessidade de inclusão das práticas consensuais de conflitos e sobre tutela coletiva que, junto das atividades complementares, deverão compor vinte por cento de uma carga horária ideal de 3700 horas, que equivale à 740 horas ao todo.

Com prazo de dois anos, as Instituições de Ensino Superior (IES) possuirão esse tempo para adaptarem seus currículos após a entrada em vigência de tais mudanças, devendo acrescentar essas e muitas outras atualizações que há anos o mercado e a realidade nacional exigem dos profissionais do Direito.

\section{NECESSIDADE DE ALTERNATIVAS PARA VIABILIZAR O ACESSO À JUSTIÇA NO BRASIL}

No relatório do CNJ, que adotou como ano-base 2017, constatou-se que os meios consensuais foram responsáveis por apenas $12,1 \%$ da solução dos conflitos, conforme demonstrado anteriormente, apesar do imenso investimento do CNJ e dos tribunais, desde 2006, em atos normativos, campanhas, sistemas e atividades de capacitação nessa área.

Dessa forma, nota-se que mesmo com mais de dez anos de fomento, por parte do Poder Judiciário brasileiro em relação às soluções consensuais de conflitos, o mesmo ainda não possui os meios ou a capacidade suficiente para atingir números substanciais que promovam o efetivo Acesso à Justiça aos cidadãos nesse sentido quantitativo.

Infelizmente, são escassos ou inexistentes dados relacionados com a qualidade de tal acesso, que investiguem se tais meios consensuais coadunam ou não com as realidades dos direitos exemplificados no tópico anterior e quais espécies de soluções são construídas e quais os números de acordos que são descumpridos. 
Reforçando-se a escolha do estudo de caso no Ceará para a análise do Acesso à Justiça nos currículos de Direito, os índices de conciliação apresentados pelo Justiça em Números de 2018 do CNJ demonstram que o referido estado possuiu o maior porcentual de conciliação entre todos os tribunais estaduais do Brasil e integra uma proporção acima do dobro nacional de conciliações entre as cinco regiões dos tribunais regionais federais.

Figura 2: Índice de conciliação, por tribunal estadual, em 2017.

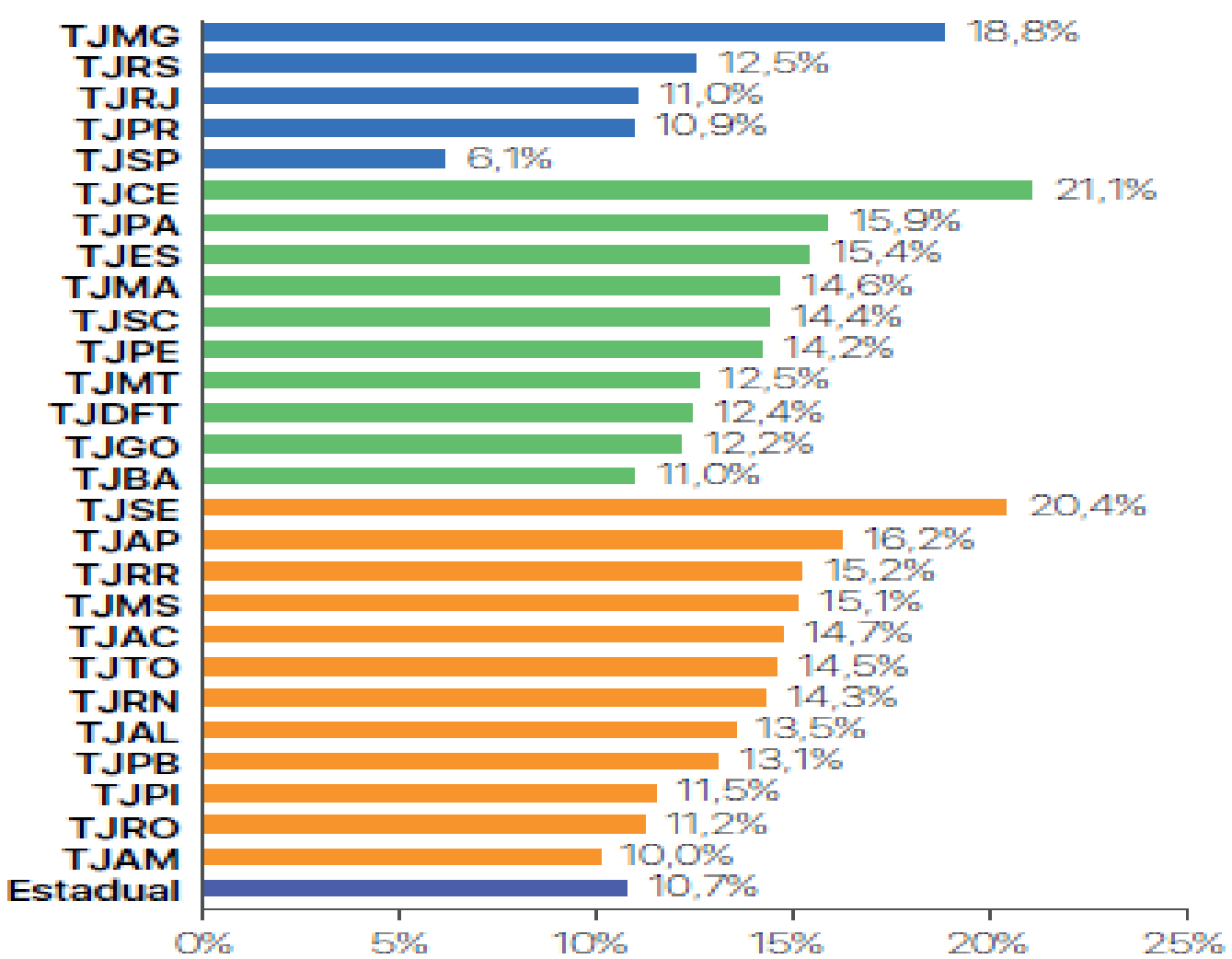

Fonte: BRASIL, 2018, p. 139

Figura 3: Índice de conciliação, por tribunal regional federal, em 2017. 


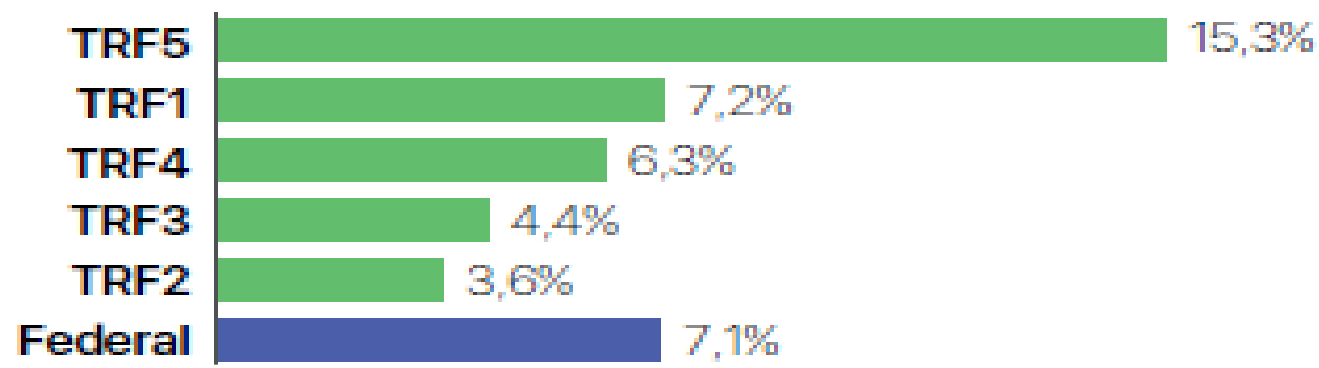

Fonte: BRASIL, 2018, p. 139

Portanto, é importante estudar o fenômeno que ocorre em terras cearenses e analisar se as matrizes curriculares dos cursos de Direito "modelo" desse estado contribuem, ou não, para o alcance de porcentuais tão elevados, quando comparados com a média nacional.

O professor da Universidade de Nova Iorque, Oscar Chase (2014, p. 150), quando versa sobre "crises de litigiosidade" - tal qual a enfrentada pelo Brasil atualmente - afirma que certas medidas podem ser adotadas pela Administração Pública para dirimir os sintomas dessa crise, como: a) aumentar o número de julgadores, b) ampliar o quadro funcional do Judiciário; e c) criar uma dilatação da jornada de trabalho dos magistrados. Entretanto, o próprio autor ressalta que todos esses aspectos seriam simplesmente paliativos, pois fenômenos como os que fomentam a "hiperlitigiosidade" do Estado, são essenciais para se perceber a importância das soluções equivalentes de composição.

A situação anteriormente exposta pode ser vista no Brasil do século XXI, em que o Judiciário assiste um número crescente de demandas serem apresentadas para distribuição entre as milhares de varas do país e os magistrados não conseguirem suprir o pleno acesso à Justiça que todos esses brasileiros buscam. Tal realidade é diametralmente oposta ao previsto no inciso XXXV do artigo quinto da Constituição Federal, que versa sobre a lei não excluir da apreciação do Poder Judiciário lesão ou ameaça ao direito dos seus cidadãos.

Para corrigir isso, o professor da universidade de Cambridge, Neil Andrews (2012), ressalta que os potenciais litigantes precisam se tornar conscientes dos diversos benefícios econômicos, sociais e até psicológicos que existem quando optam pelos meios equitativos em detrimento ao processo judicial, sendo isso parte de um crescimento orgânico e institucional da sociedade, como já ocorreu em outros países, sendo exemplos a Inglaterra e os Estados Unidos da América.

Entretanto, não é possível vislumbrar como os potenciais litigantes de um Estado poderiam compreender tais benefícios, se nem mesmo os operadores do Direito do país são 
formados para conhecê-los e apresentar isso aos seus futuros clientes, conforme irá se demonstrar.

\subsection{Estudo de caso: as disciplinas voltadas ao Acesso à Justiça nas matrizes curriculares dos cursos "modelo" de Direito no Ceará}

Dentro da análise proposta inicialmente, iremos abordar as quatro matrizes curriculares das IES que possuem pós-graduação stricto sensu no estado do Ceará, quais sejam: Centro Universitário 7 de Setembro (UNI7), Centro Universitário Christus (UNICHRISTUS), Universidade de Fortaleza (UNIFOR) e a Universidade Federal do Ceará (UFC) ${ }^{3}$.

Ressalte-se, ainda, que tal análise não se restringe apenas ao acesso à justiça, no sentido de número de conciliações, mas como princípio proporcionando bases da ordem jurídica brasileira e que permite que toda a sociedade possa usufruir da Justiça, não apenas no sentido de iniciar uma ação judicial, e sim como força necessária para alcançar um estado democrático efetivo ao reconhecer seus próprios direitos e para atingir uma pacificação social.

Iremos focar, portanto, em disciplinas que promovam o Acesso à Justiça de alguma maneira, seja do ponto de vista processual, material, teórico ou prático. Para isso, serão apresentadas as cargas horárias de cada uma logo após sua identificação e, ao final, a soma temporal dessas disciplinas em comparação com a carga horária total do curso.

Dentro das disciplinas obrigatórias dos cursos, o panorama é o seguinte:

UNI7: Ética Geral (40h); Dir. Criança e Adolescente (40h); Estágio Supervisionado IV e VI (40h e 40h): 160 horas de 4200 horas (menos de 4\% do total do curso)

UNICHRISTUS ${ }^{4}$ : Prof. jurídicas e cidadania (40h); Ética Geral e Jurídica (40h); Dir. Humanos e Fundamentais (40h); Mediação e Arbitragem (40h); Dir. Criança, Adolescente e Idoso (40h); Proteção Inter. dos Dir. Humanos (40h): 240 horas de 3920 (mais de 6\% do total do curso)*

UNIFOR: Soluções extrajudiciais de disputas (36h); Estágios IV e V (18h somados): 54 horas de 3636 horas (mais de 1,25\% do total do curso)

UFC $^{5}$ : Estágio Supervisionado II (160h): 160 horas de 3712 horas (mais de 4\% do total

\footnotetext{
${ }^{3}$ Todos os dados foram angariados nos sítios eletrônicos das referidas instituições de ensino superior.

${ }^{4} \mathrm{O}$ Centro Universitário Unichristus possui oito cadeiras de estágio, porém não dispõe publicamente de informações sobre quais fazem atendimento ao público ou se, eventualmente, alguma é voltada aos meios consensuais ou tutelas coletivas, devendo tal porcentual ser maior, caso existam disciplinas nesse sentido.

${ }^{5}$ Com a Universidade Federal do Ceará, existe o programa de ensino de conciliação e mediação, porém de maneira optativa aos alunos que cursam a disciplina de Estágio Supervisionado II, ou seja, tais discentes podem atravessar
} 
do curso).

Em face desses números, relembramos que a carga horária sugerida pelos novos parâmetros da Resolução no 5 de 2018 são de 3700 horas ao todo e que, 20\% (740 horas), deveriam ser voltadas para a prática jurídica (com meios consensuais e a tutela coletiva incluídas nessa prática) e atividades complementares.

Pelo ponto de vista "qualitativo", com disciplinas que envolvem formação e embasamento teórico dos profissionais que viabilizariam um melhor Acesso à Justiça, percebemos a escassez nas obrigatórias das matrizes curriculares, sendo oitenta horas na UNI7, duzentas horas na UNICHRISTUS e nenhuma hora sequer na UNIFOR e na UFC.

Demonstra-se, assim, a dificuldade e a pouca relevância que são tratados os assuntos relacionados com o Acesso à Justiça e suas nuances nas matrizes curriculares obrigatórias nos cursos adotados como "modelos" na experiência cearense, aspecto que provavelmente reflete no pouco conhecimento desses meios por parte dos profissionais do Direito recém graduados.

Dentro das disciplinas optativas dos cursos, o panorama é o seguinte:

UNI7: Arbitragem; Dir. das Minorias; Mediação; Relações de Trabalho e Negociação; Responsabilidade Social e Libras (todas 40h cada): 240 horas optativas possíveis.

UNICHRISTUS $^{6}$ : não obteve-se acesso às disciplinas optativas existentes.

UNIFOR: Arte e cultura brasileira (72h); Libras (36 horas); Teoria dos Dir. Humanos (36h); Dir. Culturais (36h); Dir. Infância e Juventude (72h) e Educação Ambiental (72h): 324 horas optativas possíveis.

UFC $^{7}$ : Dir. Agrário (64h); Dir. do Idoso (64h); Dir. da Criança e do Adolescente (64h); Políticas Públicas de Saúde (32h); Ciberdemocracia e Governança Virtual (32h); Dir. das Águas (32h); Dir. dos Refugiados (32h); Sindicalismo e Negociação Coletiva (64h); Dir. Desportivo (32h); Filosofia dos Dir. Humanos (32h); Acesso a Justiça e Dir. Humanos (32h); Arbitragem, Mediação e Conciliação (32h): 512 horas optativas possíveis.

Apesar da melhoria no quadro do Acesso à Justiça quando se analisa o espectro das opcionais, relembramos que disciplinas que são consideradas como obrigatórias agora na

todo o curso de Direito sem ter contato obrigatório nenhuma vez com algo relacionado ao acesso à justiça de maneira teórica ou prática, sendo o atendimento ao público de forma gratuita em petições iniciais a única forma precária de conhecimento dessa necessidade.

${ }^{6}$ Não existem informações públicas disponíveis e a solicitação feita à coordenação do referido centro universitário ainda está sendo analisada no momento da elaboração deste artigo.

${ }^{7}$ Contudo, a realidade da Universidade Federal do Ceará é que a maioria das optativas são fictícias: existem na matriz curricular, mas não são ofertadas por falta de professores. 
Resolução $n^{\circ}$ 5/2018 do CNE estão enquadradas na categoria opcional (como a arbitragem, mediação e conciliação na UNI7 e na UFC), ou são pouco relevantes no quadro geral das obrigatórias (como na UNICHRISTUS e na UNIFOR, que dedicaram quarenta ou trinta e seis horas, respectivamente, aos meios consensuais como um todo em suas matrizes curriculares).

Além desse aspecto, exatamente por serem opcionais, existe grande possibilidade do discente escolher poucas ou nenhuma dessas voltadas ao acesso à justiça em sua formação como profissional.

Tais condições das matrizes curriculares podem ser um reflexo exatamente de uma das dificuldades em se implementar com efetividade um Acesso à Justiça no Brasil, quando os próprios profissionais não possuem um foco em suas formações basilares nesse princípio.

Pondera-se, dessa forma, que fatores externos devam ser os maiores influenciadores dos altos índices de conciliação que essa unidade federativa possui em comparação com as restantes do país, em face das matrizes curriculares dos cursos "modelo" de graduação em Direito no Ceará e a consequente formação deficiente dos profissionais recém formados nessa área não poderem ser consideradas como fundamentais nesse aspecto.

Existe, também, a hipótese que, nos demais estados, uma atenção e relevância ainda menores possam ser dadas pelos currículos dos seus cursos de Direito ao Acesso à Justiça (algo que se considera remoto, por decorrência dos já bastante baixos porcentuais de disciplinas voltadas para tal área de estudo nas graduações analisadas no Ceará). Entretanto, a averiguação de tal possibilidade exigiria um estudo mais aprofundado de todos os currículos de cursos "modelo" do Brasil, que não é o objetivo deste ensaio.

Portanto, provavelmente outros fatores no Ceará, como políticas públicas, relevância de pensadores nacionais sobre a temática localizados neste estado, formação de profissionais em nível de pós-graduação para valorizar este princípio e sua aplicabilidade, questões culturais da própria sociedade e os litígios que lhe são peculiares e aspectos outros voltados ao fomento do Acesso à Justiça, possam ser o reflexo dos altos números de conciliações que o caso cearense apresenta. Contudo, dependendo da formação básica do profissional do Direito, mostrou-se verdadeira carência nesse sentido.

\section{ALINHANDO AS MATRIZES CURRICULARES COM AS EXIGÊNCIAS LEGAIS E A REALIDADE REGIONAL}

Como foi possível notar até o momento, é evidente que o Acesso à Justiça precisa de 
um esforço que inicia não apenas no Poder Judiciário, mas em outras vias também, sendo a formação dos discentes do Direito uma delas.

Dentro do panorama cearense, foi analisado que tanto do ponto de vista qualitativo como quantitativo, o ensino de disciplinas que possuem relação com o Acesso à Justiça são atualmente bastante desconsiderados na formação básica do profissional do Direito, nunca ultrapassando sete por cento da carga horária total das disciplinas obrigatórias de nenhuma matriz curricular analisada e chegando ao cúmulo de, em metade dos cursos analisados, ter nenhuma hora dedicada à formação humana dos discentes (com o ensino de disciplinas voltadas para minorias, direitos humanos, aspectos culturais e de diferenciação das necessidades dos seres humanos e etc.).

A carga horária optativa, apesar de ofertar possibilidades sobre tal formação, como o próprio nome informa não são obrigatórias aos alunos e, em casos como os da UFC, sequer são ofertadas por falta de profissionais para lecionar tais disciplinas.

A realidade é que os cursos de Direito particulares, infelizmente, acabam se focando na preparação dos seus discentes para provas de $\mathrm{OAB}$ e concursos (aspectos que trazem mais alunos aos seus quadros ou menos, dependendo dos resultados) e os cursos de Direito Público (como o da UFC), que supostamente não precisaria ter tamanha preocupação com isso, é o mais deficiente quando se trata do Acesso à Justiça, quando na verdade deveria ser pioneiro nessa área.

Neste momento, cabe reproduzir a crítica que Edmundo Lima de Arruda Júnior procede quanto ao ensino do Direito nas universidades públicas.

\begin{abstract}
Acredito que o ensino do direito em universidades públicas enfrenta o maior desafio histórico para dar contemporaneidade a uma educação jurídica efetivamente transformadora do seu entorno e em direção a outras dimensões da vida. Todavia esse desafio revela um paradoxo. Se nas escolas particulares, a lógica do mercado condiciona e limita o avanço da crítica, tomada como condição compreensiva dos sentidos da dogmática jurídica, nas escolas públicas universitárias encontramos ao mesmo tempo em maior grau tanto as forças da potência como as da (des)potência daquele projeto de modernização socioeducacional.(ARRUDA JÚNIOR, 2012, p.126 e 127, grifos no original).
\end{abstract}

Coadunando com a opinião do autor, exatamente as instituições públicas (como a UFC, que faz parte do grupo aqui analisado), é que tinham o potencial para exercerem experiências de melhoria do ensino jurídico e enfoque em questões como a abordada neste ensaio, referentes ao acesso à justiça, sem precisar se algemar aos requisitos mercadológicos exclusivamente. 
Entretanto, exatamente nela que se percebe o maior retrocesso na temática quando em comparação com as outras três particulares analisadas, quando em suas disciplinas obrigatórias não possui simplesmente nenhum embasamento teórico para a prática efetiva do acesso à justiça pelos seus discentes.

Ora, se a nova Resolução sobre as Diretrizes Nacionais Curriculares dos Cursos de Direito fomentam, entre outras coisas, a busca pela vocação do curso, nada mais lógico seria que instituições de ensino do Direito que se localizam no estado com os melhores índices de conciliação do país estivessem focando nessa espécie de formação para os seus alunos e, os cursos públicos, possuiriam ainda em maior quantidade tal responsabilidade.

Tal crítica, inclusive, poderia se estender para outras áreas de ensino que os cursos cearenses não se focam em face da sua realidade regional, mas que aqui não foram o objeto do estudo. Porém, apenas a critério de curiosidade, questões de direito agrário (dificuldade das terras improdutivas e da produção do pequeno agricultor), direito aduaneiro (por ter dois portos no Estado), direito das águas (pelas dificuldades sazonais que o sertão cearense sofre pela falta dessa e má distribuição de tal recurso) e outras espécies de formação jurídica, voltadas para as carências e necessidades da região cearense, também poderiam (e deveriam) ser incluídas nas matrizes curriculares.

Acredita-se, contudo, que o Acesso à Justiça é algo que similarmente deve ser buscado por todas as regiões do Brasil e, exatamente por esse fator, que tal trabalho se faz relevante, para demonstrar a falta de estrutura básica na formação discente em um caso concreto para suprir essa temática, que deveria ser prioridade nacional.

\section{CONSIDERAÇÕES FINAIS}

Após a demonstração de um dos vários problemas que a formação dos discentes do Direito precisará ser enfrentado, é que se percebe as dificuldades diversas que as novas Diretrizes Nacionais Curriculares trarão consigo e, principalmente, como ainda em aspectos da Resolução de 2004 existem diversas deficiências que a grande quantidade de cursos jurídicos do país não conseguiram suprir.

Dentro das diversas perspectivas e incentivos à mudança que a nova regulação sobre o referido tema traz consigo, assim como ocorreu com as diretrizes de 2004, não se acredita que algo possa efetivamente mudar o cerne da crise do ensino jurídico pátrio que não seja um trabalho conjunto da mudança de perspectiva sobre o que é um profissional do Direito. Tal 
fator, contudo, não depende apenas das IES.

Conforme se demonstrou, apesar dos números apontarem para uma hipótese, o estudo do caso concreto demonstrou que pouco se debate e leciona sobre o acesso à justiça e garantias que gravitam em torno desse princípio nas IES, sendo a solução da crise de litigiosidade nacional algo que vai bem além das matrizes curriculares e da formação dos futuros bacharéis em Direito.

Afinal, enquanto em uma prova de OAB - com altos índices de reprovação ano após ano - e que possui oitenta questões, existirem apenas quatro dessas dedicadas, ainda que de maneira indireta, ao Acesso à Justiça: duas de direitos humanos e duas voltadas para à infância e adolescência (desconsiderando-se aqui as questões de ética profissional), não se pode dizer que os filtros que a própria classe advocatícia coloca como relevantes aos seus profissionais estejam considerando as necessidades do estudo de tal temática.

Continuando neste aspecto, uma prova de seleção, seja da $\mathrm{OAB}$ ou para adentrar em alguma carreira pública, que não se foca nos problemas regionais de cada realidade brasileira e nos direitos que cada camada populacional mais carece em cada situação, são certames que demonstram um descompasso completo entre o que idealizamos como profissional do Direito na área pedagógica com o que cobramos destes para exercerem suas funções no setor estatal.

Dentro das provas de concurso público, raramente vemos questões de Acesso à Justiça, geralmente sendo essas voltadas ao direito material e processual, em aspectos mais legalistas e pouco concretas, condição material essa que tal princípio necessita para um funcionamento efetivo, praticado e aplicado por um jurista com formação humanística.

Evidente, assim, que não podemos culpar apenas as IES pelo atual descaso com o ensino do Acesso à Justiça, pois se os próprios órgãos de seleção de entrada no Judiciário (seja pela $\mathrm{OAB}$ ou pela via pública), não se importam com a temática, como poderiam os formadores dos futuros profissionais do Direito se preocuparem com isso e correrem o risco de formar seus profissionais de maneira deficiente, em aspectos que são mais relevantes para os filtros de entrada no mercado?

Porém, talvez seja hora de considerar que tanto os filtros mercadológicos quanto as IES estão desatualizados em relação à realidade complexa que vivemos no Brasil e no mundo, com necessidades e direitos cada vez mais rebuscados e inter-relacionados, com a ascensão dos direitos coletivos e das vozes das minorias e um número crescente de lides que o Judiciário não consegue suprir mais. 
Infelizmente, tudo o que foi aqui falado não são meras suposições, são simplesmente os números do Judiciário que demonstram a necessidade de revermos nossos conceitos sobre a realidade brasileira e admitir que o Acesso à Justiça não consegue ser efetivo.

Sofre-se o risco com essas novas Diretrizes Nacionais Curriculares do curso de Direito, novamente, do Acesso à Justiça (em suas mais diversas formas), ser apenas mais um entre tantos critérios escritos em uma folha de papel por formadores educacionais idealizadores, mas que não possuem auxílio da comunidade jurídica para implementar algo que faça a crise do ensino jurídico ser debelada.

Para isso, mudanças, sejam pequenas ou grandes, precisam ser enfrentadas em conjunto por todos os componentes do mundo jurídico: OAB, Judiciário, IES, professores e alunos precisam cooperar e concordarem, entre si, qual será o futuro jurídico do país. Afinal, as mudanças estão chegando, novas tecnologias surgem, profissões que hoje existem em breve não mais existirão e o local que ao profissional do Direito caberá em tudo isso ainda permanece incerto.

\section{REFERÊNCIAS}

ANDREWS, Neil. O moderno processo civil: formas judiciais e alternativas de resolução de conflitos na Inglaterra. $2^{\mathrm{a}}$ Ed. Tradução do autor [orientação e revisão da tradução Teresa Arruda Alvim Wambier]. São Paulo, Editora Revista dos Tribunais, 2012.

ARRUDA JÚNIOR, Edmundo Lima de. Educação Jurídica e Universidade Pública. In: RODRIGUES, Horácio Wanderlei e ARRUDA JÚNIOR, Edmundo Lima de (Org.). Educação Jurídica (Coleção Pensando o Direito no Século XXI; v.2). Florianópolis: FUNJAB, 2012, p. 125-136.

BRASIL. Conselho Nacional de Educação. Câmara de Educação Superior. Resolução no 9, de 29 de setembro de 2004. Institui as Diretrizes Curriculares Nacionais do Curso de Graduação em Direito e dá outras providências. Diário Oficial da União, Brasília, DF, $1^{\text {o }}$ out. 2004. Disponível em: <http://portal.mec.gov.br/cne/arquivos/pdf/rces09_04.pdf>. Acesso em: 06 dez. 2018.

BRASIL. Conselho Nacional de Educação. Câmara de Educação Superior. Parecer no 635, aprovado em 04 de outubro de 2018. Revisão das Diretrizes Curriculares Nacionais do curso de graduação em Direito. Disponível em: https://www.migalhas.com.br/arquivos/2018/10/art20181030-11.pdf >. Acesso em: 06 dez. 2018.

BRASIL. Justiça em Números 2018: ano-base 2017. Conselho Nacional de Justiça - Brasília: CNJ, 2017, p. 73.

CAPPELlETTI, Mauro; GARTH Bryant. Acesso à justiça. Porto Alegre, Sérgio Antonio 
Fabris, 1988.

CHASE, Oscar G. Direito, cultura e ritual: sistemas de resolução de conflitos no contexto da cultura comparada. Tradução Sérgio Arenhart e Gustavo Osna. São Paulo, Marcial Pons, 2014, p.150.

LIMA, Stephane Hilda Barbosa. Formação jurídica, metodologias ativas de ensino e a experiência da graduação da Escola de Direito de São Paulo (FGV DIREITO SP). 173 f. : il. Dissertação (mestrado) - Universidade Federal do Ceará, Faculdade de Direito , Programa de Pós - Graduação em Direito , Fortaleza, 2018.

MAROCCO, Andréa de Almeida Leite. O Ensino Jurídico: Desafios para a Formação do Profissional do Século XXI. In: RODRIGUES, Horácio Wanderlei e ARRUDA JÚNIOR, Edmundo Lima de (Org.). Educação Jurídica (Coleção Pensando o Direito no Século XXI; v.2). Florianópolis: FUNJAB, 2012, p. 75-122.

NEVES, Marcelo. Transconstitucionalismo. São Paulo, WMF Martins Fontes, 2009, p. 297

RODRIGUES, Horácio Wanderlei. Diretrizes Curriculares Nacionais dos Cursos de Direito: análise da minuta de resolução apresentada pelo CNE como texto referência para a audiência pública de julho de 2018. In: RODRIGUES, Horácio Wanderlei; CELLA, José Renato; SILVA, Jaqueline Mielke. Direito, Democracia e Sustentabilidade: Anuário do PPGD/IMED. Erechim, RS; Deviant; 2018. p. 25-59.

WOLKMER, Antônio Carlos. Introdução aos Fundamentos de uma Teoria Geral dos "Novos" Direitos. Revista Jurídica - UNICURITIBA, Curitiba, v. 2, n. 31, p. 121-148, 2013. Disponível em: <http://revista.unicuritiba.edu.br/index.php/RevJur/article/view/593>. Acesso em: 7 de set de 2017. 